\title{
Microwave-assisted Sintering of Amorphous Powders
}

\author{
Hoikwan Lee ${ }^{\dagger}$ Kimin Kim*, Mankyu Park*, and Wonho Kang* \\ Materials Research Institute, The Pennsylvania State University, University Park, PA 16802, USA \\ *Department of Advance Materials Science and Engineering, Dankook University, Cheonan 330-714, Korea
}

(Received August 14, 2010; Revised September 20, 2010; Accepted October 5, 2010)

\begin{abstract}
Microwave heating (MW) was studied for the sintering of amorphous powders. In comparison to conventional heating (CV), the results show that microwave heating has the potential to substantially accelerate the sintering process and allow for highly densified solidification by eliminating the pores and increasing the shrinkage rate. In the heat treatment to synthesize aluminum borate $\left(\mathrm{Al}_{18} \mathrm{~B}_{4} \mathrm{O}_{33}\right)$ whiskers from precursors, it was found that microwave heating helps the formation of $\mathrm{Al}_{18} \mathrm{~B}_{4} \mathrm{O}_{33}$ crystal as well as the decrease of crystallization temperature of $\mathrm{Al}_{18} \mathrm{~B}_{4} \mathrm{O}_{33}$ to a level significantly lower than the previously reported value of $1050^{\circ} \mathrm{C}$.
\end{abstract}

Key words : Sintering, Densification, Crystallization, Microwave heating, Aluminum borate

\section{Introduction}

$\mathrm{F}$ or effective materials processing (i.e. sintering, annealing, and crystallization) and the improvement of material properties, microwave processing has been studied and applied because it has the potential to provide for uniform, rapid heating, and to reduce the processing time for polymers and ceramics, which are materials with low thermal conductivities. ${ }^{1)}$

In microwave processing, the energy is delivered directly to the materials through molecular/ion interaction with the electromagnetic field, while the energy in conventional thermal processing is transferred to the materials through convection, conduction, and radiation of heat from the surface of the material. Due to its volumetric heating, microwave processing can not only achieve the rapid and uniform heating of materials, but can also be utilized for the selective heating of materials. The molecular structure affects the ability of microwaves to interact with materials and transfer energy. So, if a sample was combined with several materials having different dielectric properties, the microwaves will selectively couple with a high loss material. Therefore, it may be possible to process multiple phase materials with new or unique micro structures by microwave processing; it is also possible to initiate chemical reactions not possible in conventional processing through the selective heating of the reactants. $\left.{ }^{1,2}\right)$

In the recent literature, many researchers have reported the effects of microwave heating, such as the enhanced reaction rate of thermosetting resins during curing, ${ }^{3)}$ faster den-

\footnotetext{
${ }^{\dagger}$ Corresponding author: Hoikwan Lee

E-mail : hoikwanlee@gmail.com

Tel : +82-42-520-5612 Fax : +82-41-520-5637
}

sification rates in ceramic sintering, ${ }^{4)}$ and formation of different microstructures during heat treatment. ${ }^{5,6)}$ Especially, the application of microwave heating for ceramic processing has received a lot of attention, because ceramics have low thermal conductivities and have to be processed at high temperature. So far, the study of microwave processing has been limited to crystalline materials, such as high purity commercial silica or alumina powders with a primary particle size of less than $1 \mu \mathrm{m}$, as the starting materials. ${ }^{7,8)}$ There have been a few reports on the sintering of glass powders with microwave processing; however, up to now, research into the microwave processing of non-crystalline or amorphous inorganic solids has been very limited, because glass powder is a poor absorber of microwaves up to a certain critical temperature. ${ }^{9,10}$

In this study, the effectiveness of microwave processing was investigated by sintering glass powders and synthesizing aluminum borate whiskers from amorphous powders. In order to evaluate and understand the effect of microwave sintering, commercial Pyrex glass powder with a particle size of 325 mesh was employed. Second, microwave heating was introduced as a new synthesis method for producing aluminum borates in the form of nano- or micro-whiskers. Aluminum borate is a remarkable ceramic material with a large elastic modulus, high strength, good chemical stability and low thermal expansion properties. However, most importantly, aluminum borate whiskers $\left(9 \mathrm{Al}_{2} \mathrm{O}_{3} \cdot 2 \mathrm{~B}_{2} \mathrm{O}_{3}\right)$ are currently employed to reinforce aluminum matrix composites because they are one of the cheapest ceramic whiskers. ${ }^{11-14}$

\section{Experimental Procedure}

\subsection{Sintering process of glass powders \\ Commercial glass powders (Pyrex 7740) with a particle}




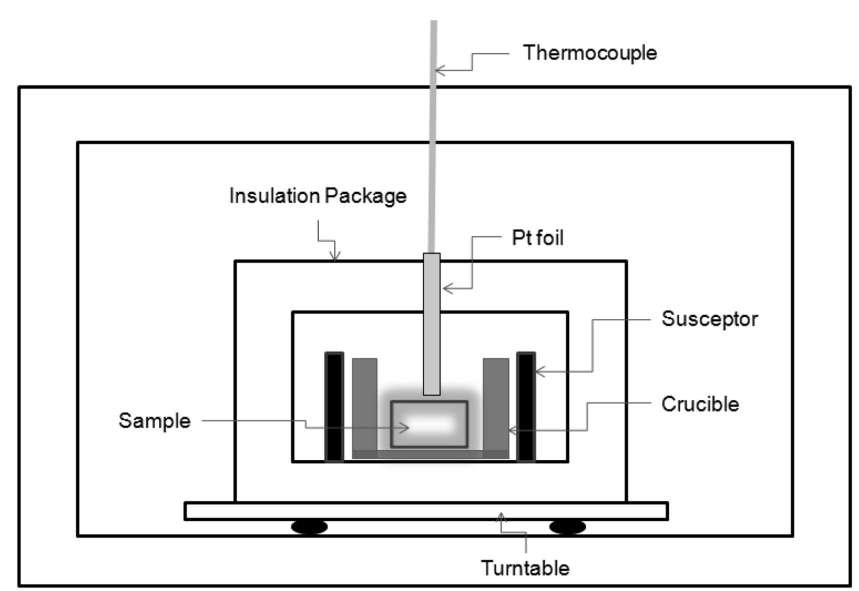

Fig. 1. Configuration of the insulation package in the microwave cavity.

size of 325 mesh were used as the raw material. The glass powders were mixed in acetone with $3 \%$ organic binder (acrylate) using a mortar and then dried in a dry oven at $105^{\circ} \mathrm{C}$. Pellets (diameter $1.3 \mathrm{~cm}$, thickness $0.3 \mathrm{~cm}$ ) were produced by uniaxial pressing (100 MPa) and then fired at $500^{\circ} \mathrm{C}$ for $3 \mathrm{~h}$ to burn out the binder. The relative green density of the compact was around $60 \%$.

Microwave-assisted sintering was carried out in a kitchen microwave with a power of $1 \mathrm{~kW}$ at $2.45 \mathrm{GHz}$ in multimode. This furnace was equipped with a Eurotherm 2404 temperature controller. The sample was loaded in an alumina crucible and then placed in the center of a thermal insulation package made of light and porous Fiberfrax Duraboard 3000 (Unifrax Corp., Niagara Falls, NY). The temperature of the sample was monitored with a shielded S type thermocouple introduced from the top of the furnace with its tip placed slightly above the sample. The thermocouple was shielded with platinum foil to prevent the microwave field from interfering with the EMF (electromotive force) signal. $\mathrm{SiC}$ was used as a susceptor to help microwave absorption of the glass powders at low temperature. The sample was heated at a rate of $10^{\circ} \mathrm{C} / \mathrm{min}$ from room temperature to the firing temperature $\left(740 \sim 850^{\circ} \mathrm{C}\right)$, followed by soaking for $20 \mathrm{~min}$ and then cooled down to room temperature before extracting the sample from the oven. For comparison, the same experiment was carried out with a conventional furnace. Fig. 1 shows a schematic design of the insulation package in the microwave cavity.

The densities of the sintered Pyrex glass samples were measured by the Archimedes' method. The microstructures were observed with an Olympus BX60M optical microscope (Olympus Optical, Tokyo, Japan) and the transmittance was measured using a CARY2300 (Varian, Texas) spectrophotometer. The residual [OH-] concentration of the sintered samples was analyzed by infrared absorption spectroscopy (FT-IR, Bruker Optics Inc., Billerica, MA).

\subsection{Synthesis of aluminum borate whiskers}

Amorphous powders (Aluminum borate precursor of the Schott Glass) were used as the raw material. The precursor prepared by sol-gel method was heated in a muffle at $600^{\circ} \mathrm{C}$ for $4 \mathrm{~h}$ to remove any impurities remaining in the final products; finally white powders were obtained. The same process explained in "sintering process of glass powder" was used for pelletizing and sintering. Thermal gravimetric and differential thermal analysis (TG-DTA, SDT 2690, TA Instruments, New Castle, DE) with the raw powder were carried out in air with a heating rate of $10^{\circ} \mathrm{C} / \mathrm{min}$. The crystal phase of the microwave and conventional samples was characterized by the X-ray diffraction (XRD, Scintag PADV, Scintag Inc., Cupertino, CA) and the microstructure was observed by the scanning electron microscopy (SEM, Hitachi S-300H, Hitachi High-Technologies Co., Tokyo, Japan).
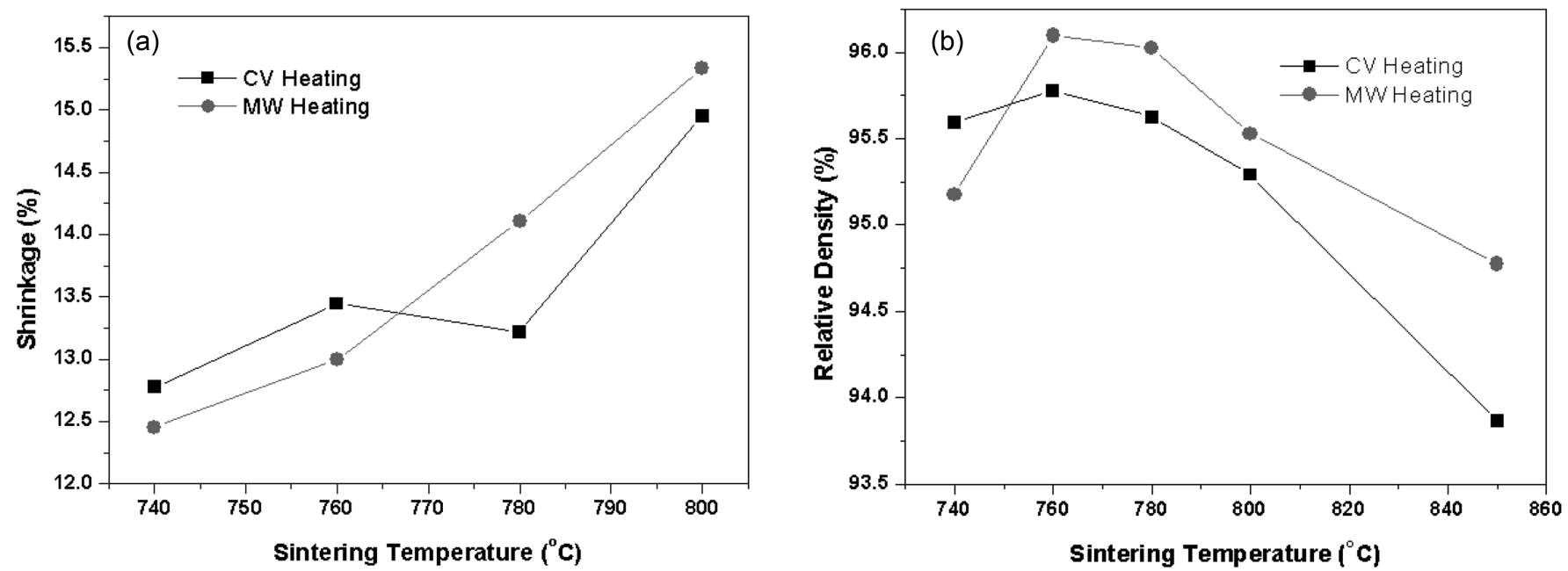

Fig. 2. Shrinkage (a) and relative density (b) of the sintered bodies treated by CV and MW heating at various temperatures for $20 \mathrm{~min}$. 

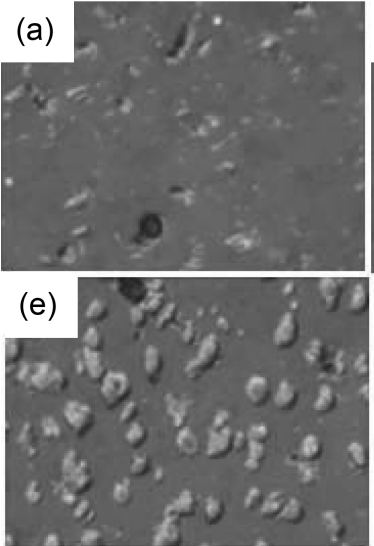

$\left[740^{\circ} \mathrm{C}\right]$
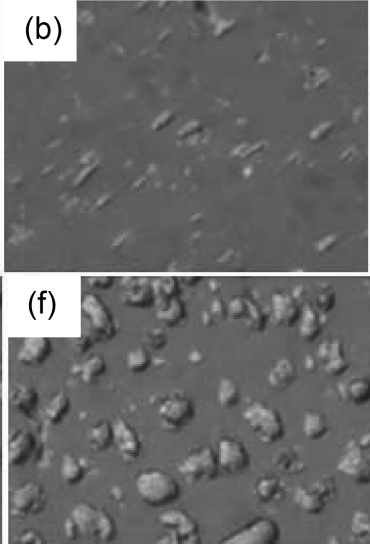

$\left[760^{\circ} \mathrm{C}\right]$
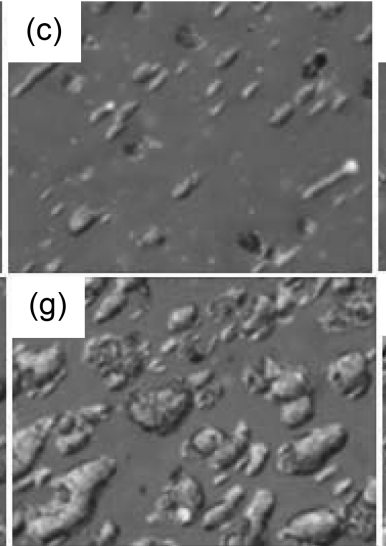

$\left[780^{\circ} \mathrm{C}\right]$
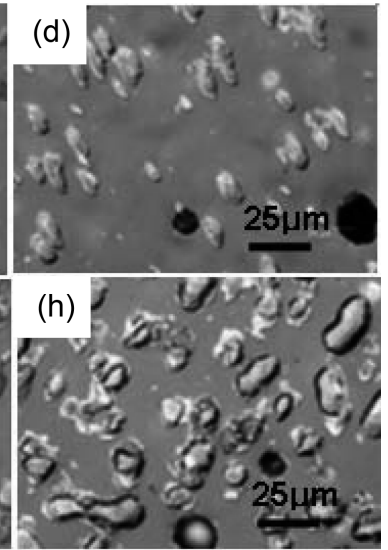

$\left[800^{\circ} \mathrm{C}\right]$

Fig. 3. Optical micrographs of the polished surface of the samples sintered at various temperatures; (a) (d) MW heating, (e) (h) CV heating

\section{Results and Discussion}

\subsection{Densification and transparency of glass powder sintered by microwave heating}

Fig. 2 shows the percentage shrinkage and relative density of the sintered bodies treated by conventional heating (CV) and microwave heating (MW) at various temperatures $\left(740^{\circ} \mathrm{C} \sim 850^{\circ} \mathrm{C}\right)$ for $20 \mathrm{~min}$. The samples shrank continuously with increasing temperature up to $800^{\circ} \mathrm{C}$ and it can be seen that the MW sintered samples show more rapid shrinkage than the CV sintered ones. Maximum relative densities of 96.1\% and 95.8\% were obtained for the MW and CV sintered samples, respectively, from the density-temperature curve after sintering at temperatures of around $760^{\circ} \mathrm{C}$. No further significant increase in the relative densities took place. Thermal treatment at higher temperatures caused a slight decrease in the relative density of the samples.

Fig. 3 shows the optical microscopy images of the polished surfaces of the sintered bodies according to the sintering temperature and heating source. As shown in Fig. 3, samples $(\mathrm{e} \sim \mathrm{h})$, sintered by CV heating, have many micro pores on the surface, which would be expected to act as an outlet for the discharge of gas trapped inside the body. Fig. 3(a d) shows the polished surfaces of samples sintered by MW heating. It is interesting to note that the residual pores are reduced in the microwave-assisted samples. Also, the size and density of the micro pores are dependent on the sintering temperature. The sample sintered at around $740^{\circ} \mathrm{C}$ has a distribution of $\sim 15 \mu \mathrm{m}$ size pores with circular shape. However, the size of the pores increased $(\sim 25 \mu \mathrm{m})$ with increasing temperature. This result clearly shows that the microwave heating reduced the porosity in the sintered body and facilitated its densification at the same time. Furthermore, it suggests that microwave heating can be used for the fabrication of sintered glassware or for the sintering of glass powders in order to endow them with new functionalities.

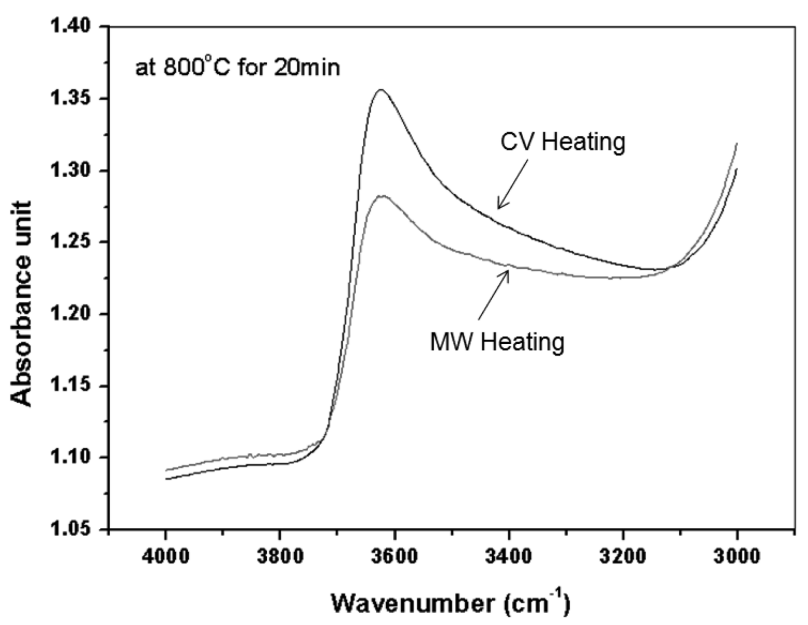

Fig. 4. IR absorbance spectra of samples sintered by $\mathrm{CV}$ and MW heating at $800^{\circ} \mathrm{C}$ for $20 \mathrm{~min}$.

As a factor influencing the optical property in sintered bodies, we suggest the presence of $[\mathrm{OH}]$ groups in the raw glass powders, because it can affect the transmittance of the sample as well as accelerate the crystallization of the cristobalite in the same manner as does oxygen. Fig. 4 shows the IR absorbance spectra of the sintered samples treated by $\mathrm{CV}$ and $\mathrm{MW}$ heating at $800^{\circ} \mathrm{C}$ for $20 \mathrm{~min}$. The amount of residual [OH-] groups of the sintered bodies was determined from the infrared absorption spectrum. As seen in Fig. 4, vibration at around $3600 \mathrm{~cm}^{-1}$ corresponding to [OH] was observed in the samples heat-treated by both the CV and MW processes. However, the intensity of the band in the MW sintered sample is lower than that of the CV sintered sample.

The transmittance measurements of the sintered Pyrex samples are shown in Fig. 5(a). The reported transmittance of Pyrex 7740 glass is $92 \%$ at a thickness of $2 \mathrm{~mm}$ in the range from $310 \mathrm{~nm}$ to $800 \mathrm{~nm}$. Compared to the melted Pyrex glass, the sintered Pyrex body possesses a much more 


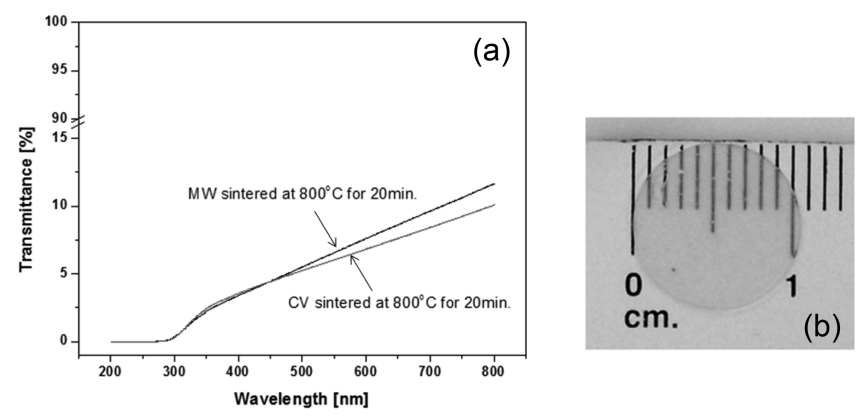

Fig. 5. (a) Comparison of transmittances of the sintered bodies with MW and CV heating and (b) appearance of the body sintered by MW heating at $820^{\circ} \mathrm{C}$ for $20 \mathrm{~min}$.

complicated microstructure that consists of grains, grain boundaries, and pores, which greatly influence the optical properties. Thus, the transmittance is still low at about $15 \%$. Furthermore, even though the microwave sintered sample was made under optimum conditions compared to the conventionally heat treated sample in terms of the pores, density, and hydroxyl groups, Fig. 5(a) shows that these factors do not have a significant effect on the transparency of the sintered sample. Instead, this experiment shows that the sintering process under vacuum atmosphere is more effective in transparency. Fig. 5(b) shows the appearance of the highly transparent samples sintered at $820^{\circ} \mathrm{C}$ for $20 \mathrm{~min}$.

In this study, we report the effect of microwave heating on Pyrex glass, which is currently used as a sealing material in laboratory glassware. Especially, the behavior of Pyrex glass powders within the viscoplastic range (log $\eta \approx 6 \sim 10$, $650^{\circ} \mathrm{C} \sim 950^{\circ} \mathrm{C}$ ) is of special interest, because the sintering and interface reactions take place at this temperature. ${ }^{15)}$

Janney and Kimrey ${ }^{16)}$ reported that the activation energy for alumina observed in microwave processing was $70 \%$ lower than that observed in the conventional process; this accelerates the material densification. When considering the sintering mechanism for ceramic materials and metals, solid-state sintering or sintering through vapor transport are the main possibilities. However, for the sintering of glass particles, the mechanism of viscous flow is more significant and this causes the transport of the material into the pore region by viscous flow. ${ }^{17)}$ Fig. 2(a) shows that the densification of the glass powder was also accelerated by the microwave heating; this means that the microwaves have an effect on the direct heating, and on the viscous flow, of the glass particles.

The position-temperature curve of glass was reported by Microwave Glass Technology World. ${ }^{18)}$ According to that report, in conventional heating, glass has a high temperature on the surface and the heat is transferred to the interior of the glass. However, in microwave heating, the inside of the glass has a high temperature. In the case of pellets made from glass powder, conventional heating can cause a viscous layer to form on the surface, because of the tempera- ture difference, and this may prevent the evaporation of gas molecules and trap them inside the sintered body. This trapped gas decreases the density; this behavior was observed in the density-temperature curve shown in Fig. 2 and in the optical micrographs shown in Fig. 3. On the other hand, microwave volumetric heating would increase the inside temperature of the glass, and the resulting viscous area would be transferred to the outside; such heat flow and microwave irradiation would remove the pores from the sintered body.

\subsection{Microwave-assisted synthesis of aluminum borate single-crystal rods}

Fig. 6 shows the curves obtained from the TG-DTA analysis of the precursors composed of $\mathrm{Al}_{2} \mathrm{O}_{3}$ and $\mathrm{B}_{2} \mathrm{O}_{3}$. During heating, two significant weight losses have been observed when the temperatures are below $500^{\circ} \mathrm{C}$ and above $1250^{\circ} \mathrm{C}$, respectively. The $23 \%$ weight loss observed at temperatures below $500^{\circ} \mathrm{C}$ is attributed to the evaporation of the physically absorbed water and/or organic solvent from the synthesized materials. The weight loss above $1250^{\circ} \mathrm{C}$ is assumed to be caused by vaporization of the boron ions. The broad exothermic peak observed at around $300^{\circ} \mathrm{C}$ is likely caused by the decomposition and/or oxidation of the side groups or side chains in the synthesized powder. The exothermic peak at $672^{\circ} \mathrm{C}$ is attributed to the crystallization of $\mathrm{Al}_{4} \mathrm{~B}_{2} \mathrm{O}_{9}$ and the weak peak at around $1050^{\circ} \mathrm{C}$ is attributed to the crystallization of $\mathrm{Al}_{18} \mathrm{~B}_{4} \mathrm{O}_{33}$.

The thermal analysis result obtained suggests that the crystallization in the synthesized precursor occurred at around $672^{\circ} \mathrm{C}$ and $1050^{\circ} \mathrm{C}$. Fig. 7 shows a comparison of the $\mathrm{XRD}$ patterns of the precursor sintered at various temperatures with different heating sources. Fig. 7(a) shows the XRD patterns of the samples sintered in the conventional furnace, showing that the amorphous powder crystallized into $\mathrm{Al}_{4} \mathrm{~B}_{2} \mathrm{O}_{9}$ and $\mathrm{Al}_{18} \mathrm{~B}_{4} \mathrm{O}_{33}$ depending on the heat-treatment temperature, as expected from the DTA curve. However,

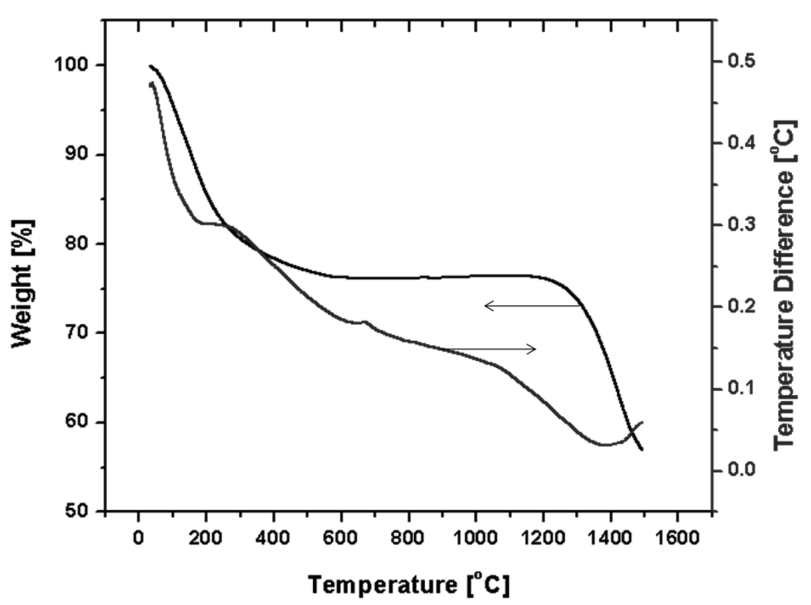

Fig. 6. Thermogravimetric and differential thermal analysis (TG-DTA curves) of the Aluminum Borate precursors synthesized by the sol-gel method. 

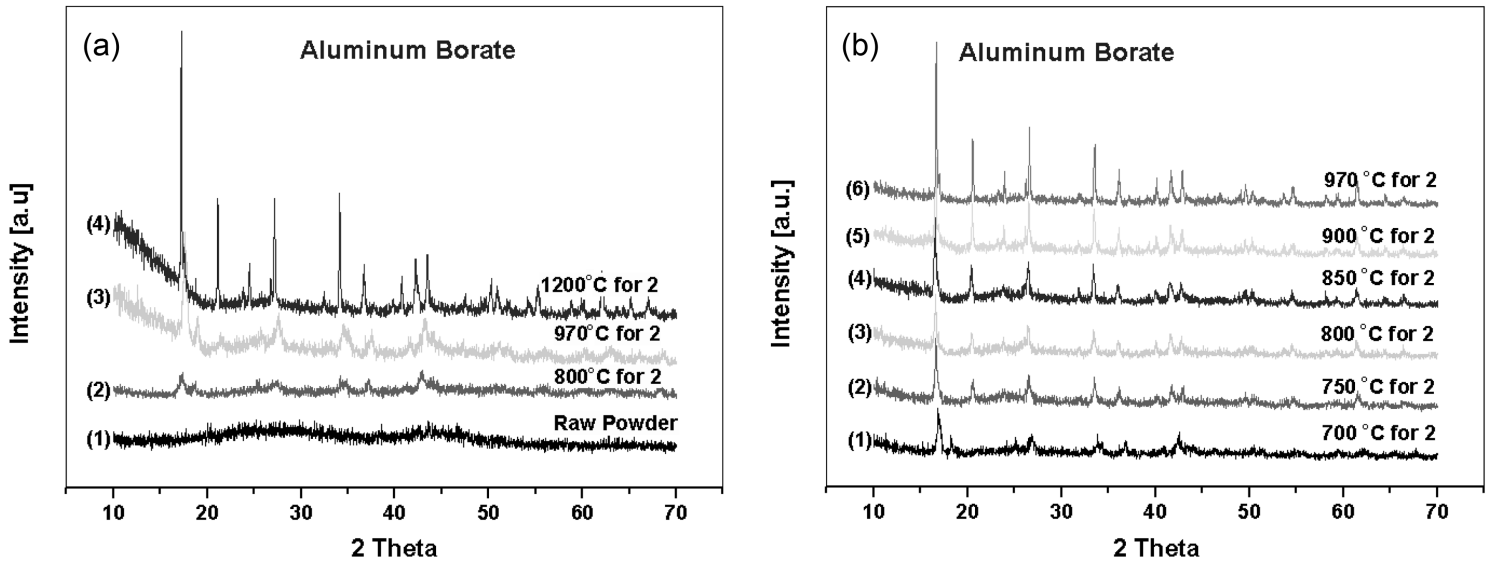

Fig. 7. XRD patterns for samples sintered by conventional heating and microwave heating at different temperatures: (a) (1) amorphous phase, (2) $\mathrm{Al}_{4} \mathrm{~B}_{2} \mathrm{O}_{9}$ \& amorphous, (3) $\mathrm{Al}_{4} \mathrm{~B}_{2} \mathrm{O}_{9}$, and $\mathrm{Al}_{18} \mathrm{~B}_{4} \mathrm{O}_{33}$, (b) (1) $\mathrm{Al}_{4} \mathrm{~B}_{2} \mathrm{O}_{9}$, (2) (6) $\mathrm{Al}_{18} \mathrm{~B}_{4} \mathrm{O}_{33}$.
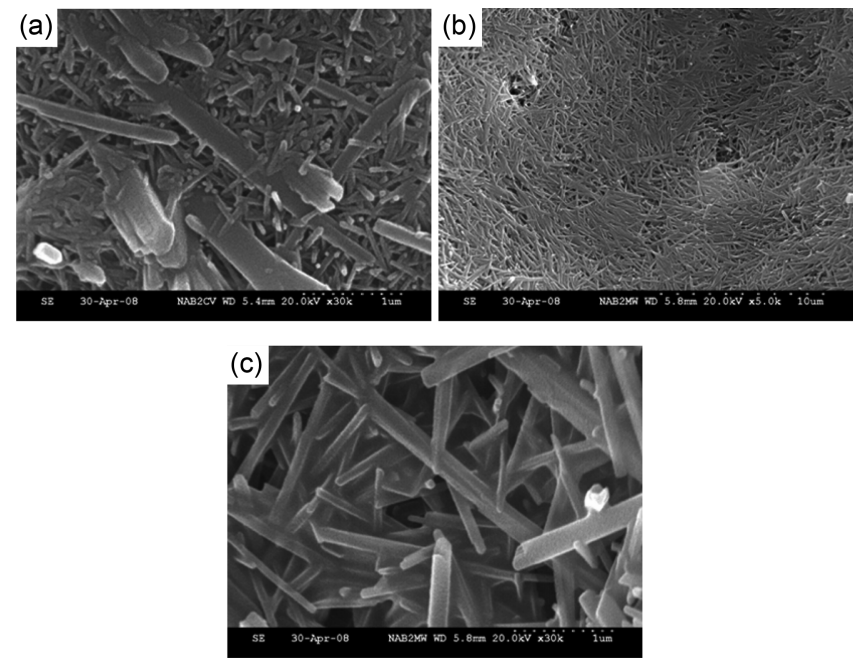

Fig. 8. Scanning electron micron micrographs of compacts sintered at $900^{\circ} \mathrm{C}$ for $2 \mathrm{~h}$ with conventional heating (a, $\mathrm{Al}_{4} \mathrm{~B}_{2} \mathrm{O}_{9}$ ) and microwave heating (b, $c, \mathrm{Al}_{18} \mathrm{~B}_{4} \mathrm{O}_{33}$ ).

when powder was sintered by microwave heating, the $\mathrm{Al}_{18} \mathrm{~B}_{4} \mathrm{O}_{33}$ crystals, which are normally formed at temperatures above $1050^{\circ} \mathrm{C}$, precipitated at as low as a temperature as $750^{\circ} \mathrm{C}$. It is interesting that the microwave heating formed $\mathrm{Al}_{18} \mathrm{~B}_{4} \mathrm{O}_{33}$ at a lower temperature compared to the conventional heating; this is not in accordance with the DTA results either. Furthermore, it is worthwhile noting that this microwave process facilitates the formation of the $\mathrm{Al}_{18} \mathrm{~B}_{4} \mathrm{O}_{33}$ crystal, which would be expected to reinforce the aluminum matrix composite.

The SEM micrograph shown in Fig. 8 shows the morphologies of the bodies sintered by conventional heating (a) and microwave heating $\left(\mathrm{b}, \mathrm{c}\right.$ ) at $900^{\circ} \mathrm{C}$ for $2 \mathrm{~h}$. Fig. 8 (a) shows that the aluminum borate crystals $\left(\mathrm{Al}_{4} \mathrm{~B}_{2} \mathrm{O}_{9}\right)$ have straight morphologies with average lengths ranging from $300 \mathrm{~nm}$ to $400 \mathrm{~nm}$ and diameters below $100 \mathrm{~nm}$; some of them have an outgrowth morphology. Fig. 8 (b, c) shows the microstructure of $\mathrm{Al}_{18} \mathrm{~B}_{4} \mathrm{O}_{33}$, which retained the original morphology of the
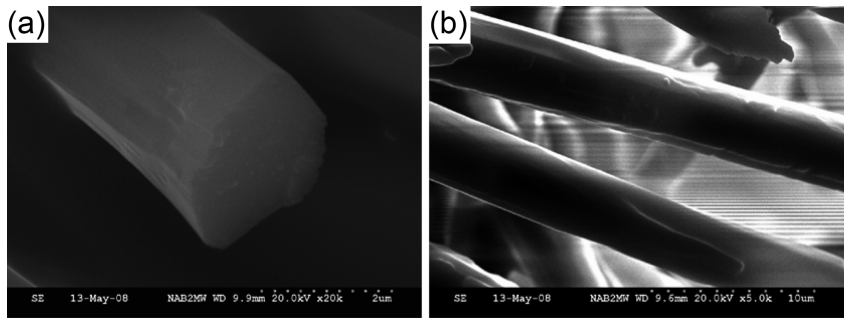

Fig. 9. Scanning electron micron micrographs of $\mathrm{Al}_{18} \mathrm{~B}_{4} \mathrm{O}_{33}$ single crystal. (a) $\mathrm{Al}_{18} \mathrm{~B}_{4} \mathrm{O}_{33}$ with hexagonal rod shape, (b) $\mathrm{Al}_{18} \mathrm{~B}_{4} \mathrm{O}_{33}$ with cylindrical rod shape.

$\mathrm{Al}_{4} \mathrm{~B}_{2} \mathrm{O}_{9}$ nanorods. These crystals are uniform and straight with an average diameter of $100 \mathrm{~nm}$ and lengths ranging from $2.5 \mu \mathrm{m}$ to $5 \mu \mathrm{m}$. There is an outgrowth of aluminum borate in the compact sintered by microwave heating as well, and the image comparison shows us that the nanorods synthesized by microwave heating are uniformly well grown compared with those done by conventional heating.

Fig. 9 shows the $\mathrm{Al}_{18} \mathrm{~B}_{4} \mathrm{O}_{33}$ nanorods grown under microwave-assisted sintering. It was observed that the $\mathrm{Al}_{18} \mathrm{~B}_{4} \mathrm{O}_{33}$ crystal has a hexagonal fracture surface and a cylindrical rod shape, as shown in Fig. 9.

As a result, the $\mathrm{Al}_{18} \mathrm{~B}_{4} \mathrm{O}_{33}$ nano- or micro-crystal rods that were formed were distributed in a well grown, three dimensional structure. Unfortunately, however, it was impossible to separate the whiskers from the bulk for the purpose of measuring their accurate length, due to the moderately high bonding strength between the crystal rods. Also, the estimated aspect ratio of the rods decreased with increasing sintering temperature and the diameter and length of the crystal rods changed from a hundred nanometers to several micrometers.

\section{Conclusions}

Microwave heating was successfully used to sinter a commercial glass powder. Glass powders having poor absorp- 
tion of electromagenctic energy were sintered and the densification was improved by reducing the trapped porosity during the solidification process. A more interesting find was observed during crystallization of aluminum borate from precursors: because of the selective interaction (or heating) between electromagnetic waves and ions, the crystallization behavior under microwave heating was not in accord with that based on DTA analysis. The results showed that microwave heating helps the formation of $\mathrm{Al}_{18} \mathrm{~B}_{4} \mathrm{O}_{33}$ crystal, as well as significantly decreasing the crystallization temperature.

\section{REFERENCES}

1. E. T. Thostenson and T. W. Chou, "Microwave Processing: Fundamentals and Applications," Composites: Part A $\mathbf{3 0}$ 1055-71 (1999).

2. D. E. Clark, F. D. Gac, and W. H. Sutton, "Microwaves: Theory and Application in Materials Processing," Ceramic Transactions, Vol. 21, pp. 50-150, Amer. Ceram. Soc., 1991.

3. E. Marand, H. R. Baker, and J. D. Graybeal, "Comparison of Reaction Mechanisms of Epoxy Resins Undergoing Thermal and Microwave Cure from In-situ Measurements of Microwave Dielectric Properties and Infrared Spectroscopy," Macromolecules, 25 2243-52 (1992).

4. D. E. Clark, D. C. Folz, C. E. Folgar, and M. M. Mahmoud, "Microwave Solutions for Ceramic Engineers," pp. 50-100, Am. Ceram. Soc., Wilet, 2005.

5. F. J. M. Almeida, J. R. Martinelli, and C. S. M. Partiti, "Characterization of Iron Phosphate Glasses Prepared by Microwave Heating," J. Non-Cryst. Solids, 353 4783-91 (2007).

6. C. Siligardi, M. C. D’Arrigo, C. Leonelli, and G. C. Pellacani, "Bulk Crystallization of Glasses Belonging to the Calcia-Zirconia-Silica System by Microwave Energy," J. Am. Ceram. Soc., 83 1001-3 (2000).
7. A. Goldstein, R. Ruginets, and Y. Geffen, "Microwave Sintering of Amorphous Silica Powders," J. Mater. Sci. Lett., 16 310-2 (1997).

8. J. P. Cheng, D. Agrawal, Y. J. Zhang, and R. Roy, "Microwave Sintering of Transparent Alumina," Mater. Lett., 56 587-92 (2002).

9. C. Siligardi, C. Leonelli, F. Bondioli, A. Corradi, and G. C. Pellacani, "Densification of Glass Powders Belonging to the $\mathrm{CaO}-\mathrm{ZrO}_{2}-\mathrm{SiO}_{2}$ System by Microwave Heating," J. Eur. Ceram. Soc., 20 177-83 (2000).

10. E. J. Minay, A. R. Boccaccini, P. Veronesi, V. Cannillo, and C. Leonelli, "Processing of Novel Glass Matrix Composites by Microwave Heating," J. Mater. Proce. Tech., 155-56 1749-55 (2004).

11. J. Wang, G. Ning, X. Yang, Z. Gan, H. Liu, and Y. Lin, "Large-scale Synthesis of $\mathrm{Al}_{4} \mathrm{~B}_{2} \mathrm{O}_{9} / \mathrm{Al}_{18} \mathrm{~B}_{4} \mathrm{O}_{33}$ Whiskers Via a Novel Method," Mater. Lett., 62 1208-11 (2008).

12. J. Wang, J. Sha, Q, Yang, Y. Wang, and D. Yang, "Synthesis of Aluminum Borate Nanowires by Sol-gel Method," Mater. Research Bull., 40 1551-57 (2005).

13. J. Zhang, J. Lin, H. S. Song, E. M. Elssfah, S. J. Liu, J. J. Luo, X. X. Ding, C. Tang, and S. R. Qi, "Bulk-quantity Fast Production of $\mathrm{Al}_{4} \mathrm{~B}_{2} \mathrm{O}_{9} / \mathrm{Al}_{18} \mathrm{~B}_{4} \mathrm{O}_{33}$ Single-crystal Nanorods by a Novel Technique," Mater. Lett., 60 3292-95 (2006).

14. C. Cheng, X. X. Ding, F. J. Shi, Y. Cheng, X. T. Huang, S. R. Qi, and C. Tang, "Preparation of Aluminum Borate Nanowires," J. Cryst. Growth, 263 600-4 (2004).

15. M. J. Pascual, A. Durán, and L. Pascual, "Sintering Process of Glasses in the System $\mathrm{Na}_{2} \mathrm{O}-\mathrm{B}_{2} \mathrm{O}_{3}-\mathrm{SiO}_{2}$, , J. Non-Cryst. Solids, 306 58-69 (2002).

16. X. P. Xie, J. L. Yang, and Y. Huang, "Densification and Grain Growth of Alumina by Microwave Processing," Mater. Lett., 37 215-20 (1998).

17. E. M. Rabinovich, "Preparation of Glass by Sintering," $J$. Mat. Sci., 20 4259-97 (1985)

18. The Microwave Glass Technology World, http://www.microwaveglass.com/ 